\title{
A PESQUISA ACADÊMICA NA AMÉRICA LATINA E NOS PAÍSES DO NORTE GEOECONÔMICO
}

\author{
José Michelson Benício Belo ${ }^{1}$
}

RESUMO: O presente ensaio problematiza examinar sobre a investigação no ensino superior, dá na América Latina e nos países do Norte Geoeconômico. Esse material deve ser continuamente alvo de discussões, porque deve atentar às necessidades do mundo contemporâneo, e necessita pesquisar sobre a influência da mesma para os estudantes ingressantes na universidade. Desse modo, a pesquisa desfrutou sobre as diferenças nos investimentos e o movimento econômico usado nos países desenvolvidos e subdesenvolvidos, encontrando uma diferença econômica em conjunto com a disparidade social.

Palavras- chave: Pesquisa. Geoeconômico. América Latina. Países Desenvolvidos. Ciência.

ABSTRACT: This essay problematizes to examine about research in higher education, in Latin America and in the countries of the Geoeconomic North. This material must be continuously discussed, because it must attend to the needs of the contemporary world, and it needs to research about its influence on students entering the university. In this way, the research took advantage of the differences in investments and the economic movement used in developed and underdeveloped countries, finding an economic difference together with social disparity.

Keywords: Research. Geoeconomic. Latin America. Developed Countries. Science.

\section{INTRODUÇÃO}

Este presente artigo tem por objetivo discutir sobre a pesquisa no ensino superior, na América Latina e nos países do Norte Geoeconômico. Esse assunto deve ser constantemente alvo de discussões, pois deve atender as necessidades do mundo atual, e necessita indagar sobre a importância da mesma para os estudantes ingressantes na universidade. $O$ texto científico é um gênero textual expositivo e argumentativo fundamentado em pesquisas, aprofundamentos teóricos e resultados de investigações sobre determinado tema. Tem

\footnotetext{
I Graduado em Letras pela FAFICA. Pós-Graduação Latu Sensu em Avaliação Educacional em língua Portuguesa pela UFPE. E-mail: michelsonpe@gmail.com.
} 
como fim principal comunicar e divulgar a ciência, assim, difundindo o conhecimento científico produzido em uma área.

A composição da independência intelectual, aparência crítica e desprender do senso comum, são direitos da escola formar, são metas que necessitam ser trabalhadas desde os anos iniciais da escolarização até o ingresso na educação superior, e por trás um grande interesse da parte docente.

A pesquisa se torna peça-chave da formação dos cidadãos, os formandos para a 'guerra' diária que demanda um olhar científico e indagador, e a experiência com a pesquisa científica traz à tona todo esse potencial humano, pois o processo de conhecimento é de extrema diversidade.

Portanto é dessa fase que sairão futuros profissionais, a investigação e a produção do conhecimento deve ser prioridade na vida acadêmica como em outros planos, assim como diz o Pesquisador Demo: "Pesquisa é o processo que deve aparecer em todo o trajeto educativo”. (DEMO, 1997, p.r6). E infelizmente é nessa etapa que a ausência de ler, interpretar e elaborar se revelam.

A união entre a pesquisa e o pesquisar é o docente e ele deve ser um firme pesquisador, é dele que vem o papel de multiplicador do costume da leitura, da escrita e da interesse, o orientador deve ser o motivador, gerando espaços para que sejam preenchidos por seus estudantes por meio da arte de pesquisar, estimular o limite da compreensão e tornar o acadêmico um pesquisador, e o educador deve entender que sua profissão não se remete em apenas transmitir o conhecimento e sim em reconstruir o conhecimento, e a ele cabe o papel fundamental.

Nesse contexto, convém ressaltar sobre o empenho da universidade para com a formação docente, possibilitar e incentivar a formação continuada e os desafios contemporâneos à volta desta tese.

Sendo um trabalho de caráter bibliográfico utilizar-se-á de base teórica para o decorrer do assunto os seguintes autores: DEMO (1996); DIANA (1996), entre outros para poder alcançar o objetivo proposto neste artigo.

\section{REFERENCIAL TEÓRICO}


Este item consiste em realizar uma revisão dos trabalhos já existentes sobre o tema abordado, que pode ser em livros, artigos, enciclopédias, monografias, teses, filmes, mídias eletrônicas e outros materiais cientificamente confiáveis.

O referencial teórico permite verificar o estado do problema a ser pesquisado, sob o aspecto teórico e de outros estudos e pesquisas já realizados (LAKATOS; MARCONI, 2003).

Segundo Marion, Dias e Traldi (2002, p.38), “O referencial teórico deve conter um apanhado do que existe, de mais atual na abordagem do tema escolhido, mesmo que as teorias atuais não façam parte de suas escolhas.”

O referencial teórico é que possibilita fundamentar, dar consistência a todo o estudo. Tem a função de nortear a pesquisa, apresentando um embasamento da literatura já publicada sobre o mesmo tema, demonstrando que o(a) pesquisador(a) tem conhecimento suficiente em relação a pesquisas relacionadas e a tradições teóricas que apóiam e cercam o estudo.

Faz-se muito importante tomar cuidado, ao realizar as citações, para que não se torne apenas uma cópia de ideias, mas, sim compreendam uma análise sobre o tema, incluindo frases ou palavras próprias do autor da pesquisa.

\section{METOdOLOGIA}

A execução desta pesquisa manifestar-se-á segundo o que Marconi e Lakatos (202I, p. 242) denominam documentação indireta, o que diz respeito à pesquisa documental e bibliográfica, consoante detalhamento a seguir.

Outrossim, apoiando-se nas lições de Bauer e Gaskell (2002, p. 39) para quem “toda pesquisa social empírica seleciona evidência para argumentar e necessita justificar a seleção da base de investigação, descrição, demonstração, prova ou refutação de uma afirmação específica" a presente pesquisa procura construir a sua base de investigação a partir de pesquisas selecionadas e, principalmente, de informações de compilações bibliográficas. Inicialmente serão analisados nos livros e nas pesquisas globalizadas pela internet, os contornos geoeconômicos da Pesquisa na América Latina e nos países desenvolvidos e, como se apresentam na prática. 
Posteriormente será feita a análise da relação entre a pesquisa na américa latina fomentado pela pesquisa nos países desenvolvidos e o cumprimento do desenvolvimento cultural da pesquisa, considerando o contexto geoeconômico.

Por fim, analisar-se-á se demonstrando a diferença entre a pesquisa em países subdesenvolvidos e países desenvolvidos, seus impactos na cultura, para saber se há, realmente, urgência em se esclarecer os contornos que os distinguem da pesquisa acadêmica e, caso necessário, apresentar uma sugestão para solucionar a possível diferença entre as pesquisas, se houver necessário.

\section{TEXTO CIENTÍFICO E PESQUISA ACADÊMICA}

A pesquisa é a investigação de problemas teóricos ou práticos por meio do emprego de técnicas científicas. Ela parte, pois, de uma dúvida ou barreira e, com o uso de método científico, busca uma resposta ou solução. É um procedimento racional e sistemático que objetiva sanar problemas, despontando em decorrência da ausência ou insuficiência de informações que possam responder ao problema.

A pesquisa acadêmica na américa latina deve ter uma trajetória metodológica que é a etapa do texto científico em que se caracterizam e especificam todas os "passos" do estudo, a partir do tipo de pesquisa que será realizado até os sujeitos (se tiver), que comporão a análise para a sua realização. É nessa etapa do projeto que se evidenciam como as ações serão desenvolvidas.

\section{ऽ RELAÇÃO DA AMÉRICA LATINA COM A PESQUISA ACADÊMICA}

As sociedades modernas são frequentemente descritas como "sociedades do saber, ou seja, do conhecimento". As tarefas econômicas, sociais, educacionais e todas as outras tornaram-se essenciais para um volume singular de cultura cognitiva.

A gestão do conhecimento está desenvolvendo produtos para mercados internacionais, que usam conhecimento intensivo para aumentar a competição entre países e empresas com base em suas habilidades científicas e tecnológicas. Mas a importância do conhecimento científico não se limita às suas consequências para o setor empresarial.

Questões como seguro ambiental, mudança climatológica, segurança, consciência de saúde preventiva, pobreza, geração de funções, equidade social, cultura geral, deterioração 
urbana e violência dependem de conhecimento singular para serem entendidas de forma pertinente e traduzidas em usos políticas efetivas. Essas necessidades são urgentes e os países precisam usar os maiores métodos de conhecimento próximo para lidar com suas questões econômicas e coletivos, visando o que comumente se entende por desenvolvimento sustentável.

Inclusive se a economia não for muito avançada e as sociedades educacionais forem de baixa qualidade, como surge constantemente na América Latina, há quase incessantemente espaço para apresentar a competência científica, não impreterivelmente a um custo muito alto. Como na economia, os benefícios sociais da acumulação da cultura não podem ser adiados para um futuro remoto, quando o desenvolvimento das instituições científicas se consolidar.

A geração de conhecimento e suas aplicações não ocorrem obrigatoriamente em sequência, e as maiores instituições científicas são as que atuam exatamente as duas coisas. Com isso, elas atraem recursos adicionais, os melhores recursos e, com o tempo, atravessam as empresas e grupos que se mantêm isolados

A ciência de ponta pode ser produzida sob circunstâncias econômicas desvantajosas; o desenvolvimento científico, a geração de empregos e a luta contra a pobreza estão interligados. A introdução de ciência, tecnologia, engenharia e inovação em nossas condições locais e específicas, assim como ocorreu em outros lugares, pode determinar o desenvolvimento equitativo. É essencial ter informação sobre casos de sucesso onde Ciência, Tecnologia, Inovação e Educação Científica (STISE, na sigla em inglês) produziram impacto contra a pobreza, ajudaram a gerar empregos $e$ fortaleceram a governança democrática. A educação e compreensão das estruturas internacionais relacionadas aos direitos de propriedade intelectual e às patentes, em todos os níveis da sociedade, é essencial, tanto para proteger a cultura étnica local e sua história e biodiversidade, como para produzir invenções locais economicamente e socialmente úteis para a sociedade local. (ORGANIZATION OF AMERICAN STATES 2005)

As instituições de didática elevada constantemente desempenharam papéis importantes em cultivar cultura e colocá-la em vantagem na sociedade. Em épocas e sociedades diferentes, estas atividades de artefato de cultura englobam desde o ensino tradicional nas profissões liberais até o prolongamento de investigação avançada nas ciências básicas e suas aplicações. 
Tradicionalmente, instituições de educação superior e científicas existiam separadamente, e a associação da ciência com a educação superior, que se considera óbvia, é, na realidade, um fato bem atual, mais típica dos países anglo-saxões do que de outros lugares, e justificada por um padrão mítico de investigação acadêmica atribuído originalmente à Universidade Humboldt na Alemanha.

De fato, a unificação de conhecimento e educação proposta por Humboldt estava mais perto do conceito filosófico de Bildung que da concepção moderna de pesquisa científica. À medida que a pesquisa científica se desenvolvia na Alemanha, na segunda metade do século 19, ela deixou as universidades e se organizou mais tarde em um arranjo institucional diferente, o Kaiser-Wilhelm Gesellschaft, atualmente Max Planck Institutes (Nybom 2007). Na maioria dos países, como na Alemanha, ciência, tecnologia e universidades se desenvolveram e se organizaram separadamente.

A educação superior se desenvolveu na região desde o século 19, inspirada pelo modelo francês, primeiro como instituições de treinamento e certificação para as profissões liberais (direito, medicina e engenharia), sob estrita supervisão do Estado, e, mais tarde, já no século 20, como um canal de mobilidade aos segmentos superiores para a crescente classe média urbana.

Alguns países, como Argentina e México, criaram universidades nacionais públicas muito grandes e semiautônomas, com centenas de milhares de estudantes, fortemente imersas na política nacional, nas quais a pesquisa, quando existia, ocorria em pequenos nichos protegidos em escolas médicas e de engenharia e, mais recentemente, seguindo o estilo americano, em institutos e departamentos de pesquisa semiautônomos.

Em outros países, tais como Brasil e Chile, a educação superior espalhou-se entre um grande número de instituições menores, públicas e privadas, em que, mais uma vez, a educação para as profissões, não a pesquisa organizada, era a força motriz

\section{A PESQUISA DOCUMENTAL COMO INSTRUMENTO ESSENCIAL E COMPLEMENTAR}

A compreensão histórica como conhecimento científico elucida significados para a pesquisa acadêmica e sobre a profissão e, para as relações que se estabelecem no cenário 
social e de saúde. Da mesma forma, o estudo histórico traz à tona acepções que contextualizam socioeconômica e politicamente a evolução profissional.

Diante disso, a pesquisa documental é o conhecimento direto e de observação da sociedade e das particularidades dos indivíduos e fatos, que emergem de testemunhos, materiais e documentos. Aos fatos será atribuída relevância a partir da interpretação e tratamento do pesquisador e, de como e que questionamentos faz às evidências. $\mathrm{Na}$ pesquisa, a utilização de documentos propicia o alcance de informações objetivas no contexto subjetivo da história.

Ao adentrar na utilização documental, faz-se mister compreender, no que tange à exploração e tratamento dos materiais, o exame desses documentos a partir do método, da técnica e da análise histórica. Os documentos aparecem como fontes e são materiais contemporâneos ou retrospectivos que contêm matérias orais e escritas, textos de gêneros diversos, vestígios e documentos administrativos, livros, e outros materiais bibliográficos.

A temporalidade é evidenciada por uma cronologia, respeito à sucessão do tempo. E a globalidade denota a investigação de todas as atividades da sociedade, coletivas e individuais. Entendemos desta forma, que a pesquisa histórica tem a documentação como método quando é universo de informações acadêmicas e apresenta processos de escolha, organização, análise e síntese. Em explicação, as técnicas correspondem ao conjunto de operações de coleta, observação e tratamento das informações, para converter os fatos em dados analisáveis.

A análise e crítica das fontes e observação documental, na metodologia investigatória, são uma obrigatoriedade. Define-se pelo conjunto de técnicas que permite constatar a confiabilidade e adequação das informações, para a apreciação e explicação de processos históricos, ou seja, apurar a credibilidade e a representatividade do material.19 Estas características, para a confiabilidade das fontes, precisam estar intimamente relacionadas aos pressupostos, hipóteses dos fatos a serem estudados e a decisão metodológica.

A confiabilidade requer, para a crítica documental, variadas técnicas, as quais incluem arqueologia, laboratórios, técnicas arquivistas, críticas textuais e, principalmente, conhecer a história da fonte. Para iniciar uma pesquisa documental, na perspectiva histórica, é imprescindível que o pesquisador se aproprie dos locais onde pode encontrar os materiais 
de análise, e as fontes que são importantes para responder à hipótese e ao método do estudo em pauta e, além disso, se essas fontes são confortáveis e comparáveis.

A confrontação é a atividade de experimentação, que relaciona informações e confirma os fatos elencados pela hipótese, para validação. A comparação aparece na pesquisa histórica para explicar os dados, as realidades postas e eventos de acordo com as teorias definidas para o estudo. Quando o pesquisador busca a instrução em documentos, para fundamentar a pesquisa precisa classificar as fontes históricas para empreender a avaliação desses documentos e para imprimir relevância ao estudo histórico.i9

O pesquisador dispõe de critérios de classificação do material científico que se referem à procedência das fontes diretas ou indiretas; a intencionalidade que pode se apresentar como voluntária ou involuntária; critério de qualidade que constitui o material e/ou cultural; e, o critério quantitativo que analisa a fonte advinda de meios tecnológicos, digitalizados e informatizados.

A argumentação escrita tem em seu rol de elementos de investigação, a arquivística, ou bibliográfica e a hemerográfica. A principal centra-se na documentação de arquivo, de informações factuais, papiros, inscrições ou manuscritos. A fonte bibliográfica caracterizase pela pesquisa de materiais acadêmicos, como teses, dissertações, artigos científicos, livros, e, a terceira, o material hemerográfico corresponde aos estudos decorrentes da imprensa, censos, informes, anuários, estatísticas, obras seriadas.

Com os arquivos escolhidos e explorados, o cuidar do investigador reflete para a pesquisa das informações, que emergem do material histórico. É uma etapa em que o pesquisador compreende os fatos, os interpreta, sintetiza as informações e, os estuda em consonância com o referencial teórico, objetivo e contexto em estudo.

A demanda por documentos na pesquisa histórica está relacionada à escrita histórica, à linguagem utilizada, aos símbolos e signos dos próprios documentos e à riqueza do conhecimento traduzido em conteúdo pelos pesquisadores.

\section{PAÍSES DESENVOLVIDOS E A PESQUISA ACADÊMICA}

Nos países desenvolvidos, o financiamento da ciência universitária é público. Para quem está em dúvida, esses números mostram claramente que, nos países desenvolvidos, as 
universidades e outras instituições de pesquisa são financiadas principalmente por fontes públicas, até mesmo universidades que cobram mensalidades.

Nos Estados Unidos, 6o\% do financiamento da pesquisa vem dessa fonte, na Europa, $77 \%$. Há poucas semanas, a fim de garantir "prosperidade a longo prazo", a Alemanha anunciou que iria investir 160 bilhões de euros em ensino superior e pesquisa científica nos próximos dez anos. Embora o Brasil enfrente desafios desconhecidos dos países mais ricos, mesmo aqui é impossível imaginar desenvolvimento sem cuidar desse setor.

Em muitos países desenvolvidos, para formular e implementar políticas de ciência e tecnologia, é necessário reunir alguns elementos básicos que constituem o plano de desenvolvimento do plano nacional de ciência e tecnologia, enfatizando:

a) A autonomia de acadêmicos e cientistas nas mais diversas áreas de produção do conhecimento;

b) Fundos públicos para dar suporte necessário ao desenvolvimento e aprimoramento da própria pesquisa;

c) Livre acesso ao conhecimento - o caráter público do conhecimento, quer em termos de cientistas que expõem e desenvolvem as suas descobertas, quer em termos de cidadãos, utilizando e integrando a aquisição de novos conhecimentos como um assunto público;

d) Formação de recursos de alta capacidade levando em consideração cientistas e formar futuros cientistas em diferentes áreas do conhecimento, bem como cientistas diretamente relacionados a projetos específicos de $\mathrm{P} \& \mathrm{D}$ no país;

e) Uma visão de longo prazo dos resultados obtidos, levando em consideração alguns estudos apresentam previsões relevantes e monitoram seu desempenho em resultados parciais e níveis de intervenção contínua até que eles Total geral;

f) A incerteza inerente às atividades de desenvolvimento científico e a imprevisibilidade da apropriação e aplicação indevida do conhecimento gerado, ou seja, o resultado de uma pesquisa;

g) a viabilização de infra-estrutura da pesquisa - todos os demais itens devem ser vistos de forma articulada entre si e a este último como instrumentos indissociáveis e articulados tanto no planejamento, quanto na operacionalização da pesquisa. (Costa, 2003, p. 120) 
Em todos os países Desenvolvidos a tecnologia constitui-se num dos pilares do crescimento econômico. Para efeitos de exemplificação destacou-se a realidade de investimentos e políticas para o setor de pesquisa e tecnologia.

Nos Estados Unidos, a tecnologia é entendida como essencial instrumento do sucesso industrial, ao lado do rendimento, capital de custo e capacidade gerencial, logo, não como um fim em si mesma, isto é, constitui-se como componente responsável pela saúde e realidade da pesquisa na empresa atrelada a outros elementos interdependentes no processo de inovação, incluindo o design, o crescimento, a manufatura, a infraestrutura, a organização e recursos humanos.

\section{PESQUISA COMO FONTE DE DESENVOLVIMENTO}

Segundo o professor Carlos Brito Cruz, diretor científico da Fapesp, o modelo de financiamento apropriado para a realidade brasileira é "o que quase todos os países utilizam: pesquisa em universidades é financiada majoritariamente por recursos governamentais".

Para Brito, os países sabem que para terem crescimento econômico e social é necessário utilizar recursos dos impostos para isso. "Além de ajudar a educar os estudantes a serem criativos e imaginativos em suas carreiras, a pesquisa em universidades também cria ideias fundamentais que as empresas e a sociedade vão usar no futuro. Soluções que vão para o mercado e que viabilizam o desenvolvimento econômico e social mais adiante."

Sylvio Accioly Canuto, professor titular do Instituto de Física da USP, acredita que a participação de recursos privados ou de empresas é de suma importância para a inovação, mas que a inovação se produz sobre conhecimento básico, e por isso a participação do Estado é essencial.

Segundo Accioly, no desenvolvimento de pesquisa básica e descomprometida de aplicações de curto prazo. "Há um entendimento equivocado sobre a participação do Estado. Para o avanço do conhecimento, são necessários estudos que requerem maior fôlego e que gerarão impacto num prazo maior. O Estado teve papel fundamental nos avanços científicos e tecnológicos recentes”, diz o docente, citando a empresa Apple e o desenvolvimento do iPod como um caso emblemático em que o conhecimento científico de base já estava disponível. 
Dessa forma, segundo Canuto, a forma ideal para as universidades deve contar com forte financiamento do Estado complementado por recursos atraídos de empresas. "Não há nação desenvolvida que tenha universidades fracas e desprestigiadas”, pontua.

De origem espanhola, a professora da Universidade Federal de São Paulo (Unifesp) Esther Solano fala que, ainda nos países mais ricos também não seja muito fácil para a comunidade enxergar a importância da pesquisa acadêmica para o desenvolvimento, o caso do Brasil chama a atenção pela "forma tão brutal, estapafúrdia, tosca com que os cortes nas pesquisas vêm sendo feitos."

O mentor do grande dentro de poucos órgãos privados de promoção à ciência no Brasil, o Instituto Serapilheira em conversa recente à Folha de São Paulo, Hugo Aguilaniu foi veemente: "Verba pública é o coração da ciência". Para ele, a administração pública tem que admitir esse investimento. "É como se fosse um acordo entre o governo e o resto da cadeia produtiva.

Em qualquer lugar do mundo é assim. Inclusive nos Estados Unidos, onde as indústrias investem pesadamente nas descobertas, o investimento público é bastante compacto porque as pessoas entendem esse papel. O capital público precisa colaborar com a pesquisa básica, que posteriormente irá gerar tecnologia, produto, economia para as empresas", afirmou.

Nos Estados Unidos, a Fundação Nacional de Ciência (NSF) relata que o Governo Federal investiu II 8 bilhões de dólares em pesquisa só em 2017 - valor concedido entre universidades, agências nacionais (como a Nasa) e indústria. 2,7\% do PIB norte-americano são aplicados em pesquisa, de acordo com a Unesco; o Brasil investe menos da metade: 1,3\%.

De acordo com dados da American Association for the Advancement of Science (AAAS), desde a década de 1980, o percentual do orçamento federal utilizado para investimentos em $\mathrm{P} \& \mathrm{D}$ insistiu basicamente inalterado, com gastos discricionários superiores a $10 \%$.

A professora Esther Solano, da Unifesp, disse que na sua Espanha as universidades também enfrentam falta de recursos, principalmente em tempos de crise econômica mais severa apesar de coletarem taxas anuais dos alunos. "As taxas de matrícula não garantem o autofinanciamento. Também vivemos algo parecido com o que aconteceu aqui, avaliando 
os campos ditos 'inúteis' e seguindo certa pressão social sobre cursos classificados acessórios e em relação a poucos alunos como a filosofia grega, por exemplo, foi encerrada. "

De acordo com Esther Solano, despedidas foram cumpridas em diversos lugares, principalmente em circunstâncias de crise, mas ela destacou que nunca viu discussões de "ressentimento" tão violentas e agressivas em qualquer lugar da universidade.

Embora não se oponha à entrada de recursos privados nas universidades públicas, Esther chamou a atenção para discussões mais amplas. "Eu até acho que sim. Os recursos privados podem ajudar, mas esse não é o principal problema. Acho que a educação deveria ser aberta e gratuita em princípio. De acordo com os princípios da república e da democracia: o Estado é obrigado a fornecer educação de qualidade aos seus cidadãos, porque esta é uma das formas mais importantes de eliminar a desigualdade", defendeu.

\section{CONSIDERAÇÕES FINAIS}

Concluindo o tema tratado, destaca-se a grande valor do mesmo, a falta da pesquisa dentro do nível superior de ensino alude à má formação de educandos nessa etapa, deixando de lado o acesso para um ensino de qualidade, assim:

Sem pesquisa não há ensino. A ausência de pesquisa degrada o ensino a patamares típicos da reprodução imitativa. Entretanto, isto não pode levar ao extremo oposto, do professor que se quer apenas pesquisador, isolandose no espaço da produção científica. Por vezes, há professores que se afastam do ensino, por estratégia, ou seja, porque do contrário não há tempo para pesquisa. Outros, porém, induzem à formação de uma casta, que passa a ver no ensino algo secundário e menor. Se a pesquisa é a razão do ensino, vale o reverso: o ensino é a razão da pesquisa, se não quisermos alimentar a ciência como prepotência a serviço de interesses particulares. Transmitir conhecimento deve fazer parte do mesmo ato de pesquisa, seja sob a ótica de dar aulas, seja como socialização do saber, seja como divulgação socialmente relevante." (Demo, 200I, p. 52).

Para que se tenha uma conquista na qualidade do ensino nos cursos de nível superior é fundamental que a pesquisa exerça a função primordial dentro e fora de sala de aula, e que contenha uma conexão para com a prática pedagógica do professor gerar uma formação crítica e reflexiva.

A formação do docente deve ser voltada também na qualidade da sua didática, assim como é fundamental os seus conhecimentos científicos e tecnológicos, ensinar é um dom 
que carece ser reparada a cada dia, e a pesquisa faz parte disso. Por esse motivo é preciso que a Instituição de Ensino Superior amplie com frequência planos voltados para a formação pedagógica do professor universitário.

Dessa forma, os professores devem tomar a docência em seu conjunto, incluindo ensino e pesquisa, duas dimensões que necessitam estar ligadas na construção do novo conhecimento, em que o docente deve trabalhar desde os anos iniciais da educação até o nível superior de ensino, transformando a pesquisa em temática de ensino.

\section{REFERÊNCIAS}

Pimenta, Selma G. e Anastasiou, Lea - “Docência no Ensino Superior”- São Paulo, Ed. Cortez, 2002

DEMO, Pedro. Educar pela Pesquisa. Campinas: Autores Associados, 1996.

DIANA, Daniele, Texto de Divulgação Científica. Toda Matéria, 2020. Disponível em: https://www.todamateria.com.br/texto-de-divulgacao-cientifica/. Acesso em: 04 jun. 202I

FELTRIM, Valéria Delisandra. Uma abordagem baseada em corpus e em sistemas de crítica para a construção de ambientes Web de auxílio à escrita acadêmica em português. Tese de doutorado. ICMC-USP, ı69p., 2004..

Aróstegui J. A pesquisa histórica: teoria e método. Bauru (SP): EDUSC; 2006.

https://docplayer.com.br/6235278-Pesquisa-universitaria-e-inovacao-no-brasil7.html

Silva LRC, Damaceno AD, Martins MCR, Sobral KM, Farias IMS. Pesquisa Documental: Alternativa investigativa na formação docente. In: Anais do IX Congresso Nacional de Educação e III Encontro Sulbrasileiro de Psicopedagogia, 2009 Out 26-29. Curitiba, Brasil. Curitiba (PR): PUCPR; 2009.

Joutard P. História oral: balanço da metodologia e da produção nos últimos 25 anos. In: Amado J, Ferreira MM. Usos \& abusos da história oral. cap 4. $4^{\underline{a}}$ ed. Rio de Janeiro (RJ): FGV; 200I. p.

https://docplayer.com.br/6235278-Pesquisa-universitaria-e-inovacao-no-brasil $7 . h t m l$ Acesso em: 02 jun. 2021 
${ }^{8}$ https://jornal.usp.br/ciencias/nos-paises-desenvolvidos-o-dinheiro-que-financia-aciencia-e-publico/ <Acesso em: 02 jun. 202I>

https://www.uepa.br/sites/default/files/editais/edital5518_matematica_texto2.pdf

Acesso em: 07 jun. 202I

DEMO, Pedro. Pesquisa: princípio científico e educativo. 8ª̣ed. São Paulo: Cortez, 2001.

https://www.unicamp.br/unicamp/ju/artigos/germana-barata/ciencia-como-estrategiade-desenvolvimento-de-nacao

Acesso em: 09 jun. 202I

DIGITAL REPOSITORY Economic Commission for Latin America and the Caribbeanhttps://repositorio.cepal.org/handle/11362/37942 Acesso em: I4 jun. 202I

LAKATOS, Eva Maria; MARCONI, Marina de Andrade. Fundamentos de metodologia científica. 5. ed. São Paulo: Atlas, 2003.

ECO, U.Como se faz uma tese. São Paulo: Perspectiva. 2006 